\title{
Correspondence
}

\section{Sudden deafness from stroke}

To the Editor: We would like to add to the correspondence about the possibility of an auditory Anton's syndrome in the report of sudden bilateral deafness from stroke. ${ }^{1}$ While Anton's eponymous syndrome is most closely associated with denial of blindness, in one seminal article, "About the perception of focal brain lesions by patients with cortical blindness and deafness," two of three reported cases were of denial of deafness. ${ }^{2}$

We saw a patient who, like those described by Anton, did not respond to voice or loud noises but insisted he was not deaf. As with Anton's original patients, communication was accomplished by writing down queries to which the patient would respond verbally. Our patient was a 72-year-old man with alcohol-associated dementia who was brought into the emergency room for odd behavior. He confabulated reasons why he could not hear (e.g., "the radio's on too loud," "the fan is on"). He was cheerful and engaging and told a consistent and detailed story of his migration from South Carolina to New York City decades prior, but gave vague and confabulatory answers to questions about the recent past.

$\mathrm{He}$ reported drinking Heavenly Hill Bourbon 80 proof, "one glass in the morning and one at night," every day for decades. Oddly, the only evidence of preserved hearing was that he coughed when he heard others cough, even when he could not see them. One of us (J.C.M.B.) dubbed this the "Metropolitan Opera Reflex." His ear examination was normal but he was uncooperative with BAERs and formal audiometry. MRI of the brain showed only generalized atrophy and evidence of microvascular disease.

The mechanisms of contagious coughing or yawning are unclear. We propose that our patient was cortically deaf and the preservation of acoustic cough response was mediated by pathways known to exist between the cochlear nucleus, the inferior colliculus, and descending acousticomotor pathways involved in acoustic reflexes and vocalization. ${ }^{3}$

Laura S. Boylan, Robert Staudinger, John C.M. Brust, New York, NY

Disclosure: The authors report no conflicts of interest.
Reply from the Author: I found Boylan et al.'s description of their patient with auditory Anton's syndrome quite fascinating, especially because this patient, though cortically deaf, responds mimetically to people coughing. This must involve a subcortical loop, as the authors suggest, but may also entail the activation of the precuneus or posterior cingulate regions, parts of the brain probably subserving self-reference and empathy, and which are known to be implicated in contagious yawning. ${ }^{4,5}$

It is also valuable to be reminded that Anton originally described auditory as well as visual syndromes, for most textbooks refer only to the visual form.

Oliver Sacks, MD, New York, NY

Disclosure: The author reports no conflict of interest.

Copyright $@ 2006$ by AAN Enterprises, Inc.

\section{References}

1. Sacks OW, Naumann M, Reiners K. Sudden deafness from stroke. Neurology 2006;66:293.

2. Anton G. Über die Selbstwahrnehmung der Herderkrankungen des Gehirns durch den Kranken bei Rindenblindheit und Rindentaubheit. Archiv Psychiatrie Nervenkrankheiten 1899;32: $86-127$.

3. Huffman RF, Henson OW Jr. The descending auditory pathway and acousticomotor systems: connections with the inferior colliculus. Brain Res Rev 1990;15:295-323.

4. Perreiol MP, Monaca C. One person yawning sets off everyone else. J Neurol Neurosurgery Psychiatry 2006;77:3.

5. Platek SM, Mohamed FN, Gallup GG. Contagious yawning and the brain. Cogn Brain Res 2005;23:448-452

\section{Brain death worldwide: Accepted fact but no global consensus in diagnostic criteria}

To the Editor: I recently read the article by Dr. Wijdicks, who comprehensively reviewed brain death status and guidelines worldwide. ${ }^{1}$ Unfortunately, Table $1 \mathrm{~A}$ provides mistaken information about the guidelines in Taiwan due to the incorrect extraction of the data from the cited article of Hung and Chen. ${ }^{2}$ The following should be corrected:

1. The law regulating brain death was passed by Taiwan government in 1987. Thus the law is present instead of "absent" as summarized in the table.

2 . The number of physicians is two instead of one.

3 . The observation time is 12 hours instead of 6 hours.

4. The law requires another 4 hours for defining brain death, and thus a confirmatory test is mandatory.

I hope Neurology can provide corrected information to the readers.

Sung-Tsang Hsieh, Taipei, Taiwan

Disclosure: The author reports no conflicts of interest.

Reply from the Author: I appreciate the comments by Dr. Hsieh and I apologize if I misread the legal document. The Chinese version of the legal document available to me states that two physicians are needed and in Taiwan an additional 4 hours of observation is needed after the diagnosis of brain death is made. This is in addition to the 12 hours of observation on the ventilator of a patient with a structural brain lesion before the first full brain death examination.

In my article, ${ }^{1}$ I referred to laboratory tests as confirmatory tests and it is my understanding that laboratory tests remain optional and not mandatory. Since my article was published in 2002, I have also noticed-in conversations with physicians from other countries-that there is sometimes confusion between what physicians think they should do and what the law dictates.

Eelco F.M. Wijdicks, Rochester, $M N$

Disclosure: The author reports no conflicts of interest.

Copyright $\odot 2006$ by AAN Enterprises, Inc.

\section{References}

1. Wijdicks EFM. Brain death worldwide: accepted fact but no global consensus in diagnostic criteria. Neurology 2002;58:20-25.

2. Hung TP, Chen ST. Prognosis of deeply comatose patients on ventilators. J Neurol Neurosurg Psychiatry 1995;58:75-80.

\section{Different degrees of right-to-left shunting predict migraine and stroke: Data from 420 patients}

To the Editor: The authors of this article ${ }^{1}$ suggest only embolism as a possible explanation of their findings that the size of right-toleft shunt predicts the occurrence of migraine and of stroke.
It has recently been proposed ${ }^{2}$ that migraine may be a physiologic response to hypoxia, as evidenced by its high incidence in a wide variety of hypoxia-provoking circumstances. This hypothesis would predict that increasing degrees of right-to-left shunting would, by increasing the levels of hypoxia, inflate the frequency and intensity of migraine attacks. 
It is possible that the authors' data include $\mathrm{pO}_{2}$ levels on each of the 420 patients reported and that a strong inverse correlation might be found between $\mathrm{pO}_{2}$ levels and migraine frequency and intensity. If so, it is possible that oxygen inhalation by these patients could reduce the incidence and severity of migraine attacks yet not alter the occurrence of putative embolism.

Gordon J. Gilbert, St. Petersburg, FL

Disclosure: The author reports no conflicts of interest.

Reply from the Authors: We appreciate Dr Gilbert's suggestion that right-to-left shunts may facilitate migraine through the mechanism of increasing hypoxia. ${ }^{1,2}$ It is not our policy to routinely measure $\mathrm{pO}_{2}$ saturation in patients undergoing transcranial Doppler (TCD) testing for right-to-left shunt unless desaturation is clinically suspected, which was not the case in the patients included in the study.

Comparing TCD with arterial blood gas measurement in patients without obvious pulmonary disease has yielded disappointing results in terms of the correlation between blood oxygen content and degree of the shunt, ${ }^{3}$ which means that the amount of the shunted blood is many times too small to induce a clinically significant hypoxia.

However, both the patients of Devuyst et al. and our patients were examined in the recumbent position, ${ }^{1,3}$ whereas right-to-left shunt may increase to a significant extent on standing, not only in patients with the platypnea- orthodeoxia syndrome ${ }^{4}$ but also in normal individuals. ${ }^{5}$

Dr. Gilbert's hypothesis needs to be properly tested in prospective studies aimed at assessing the variation of both $\mathrm{pO}_{2}$ and right-to-left shunt from the recumbent to the upright position.

Gian Paolo Anzola, Eustaquio Onorato, Eva Morandi, Francesco Casilli, Brescia, Italy

Disclosure: The authors report no conflicts of interest.

Copyright $\odot 2006$ by AAN Enterprises, Inc.

\section{References}

1. Anzola GP, Morandi E, Casilli F, Onorato E. Different degrees of rightto-left shunting predict migraine and stroke: data from 420 patients. Neurology 2006;66:765-767.

2. Gilbert GJ. The purpose of migraine. Florida Med Assn Quart J 2005; Oct:26-27.

3. Devuyst G, Piechowski-Józwiak B, Karapanayiotides T, et al. Controlled contrast transcranial Doppler and arterial blood gas analysis to quantify shunt through patent foramen ovale. Stroke 2004;35:859-863.

4. Cheng TO. Platypnea-orthodeoxya syndrome: etiology, differential diagnosis, and management. Cathet Cardiovasc Interv 1999;47:64-66.

5. Telman G, Kouperberg E, Sprecher E, Yarnitsky D. The positions of the patients in the diagnosis of patent foramen ovale by transcranial Doppler. J Neuroimaging 2003;13:356-358.

\section{Corrections}

\section{Randomized controlled phase II trial of glatiramer acetate in ALS}

In the Brief Communication "Randomized controlled phase II trial of glatiramer acetate in ALS" (Neurology 2006;66:1117-1119) by P.H. Gordon, C. Doorish, J. Montes, et al., the fourth author's name is misspelled. It should be R.L. Mosley.

This error was corrected on www.neurology.org on August 21, 2006. The publisher regrets the error.

\section{Diagnostic performance of spectroscopic and perfusion MRI for distinction of brain tumors}

In the article "Diagnostic performance of spectroscopic and perfusion MRI for distinction of brain tumors" (Neurology 2006;66:18991906) by M.A. Weber, S. Zoubaa, M. Schlieter, et al., on page 1901, line 9 “...the serial T2-weighted images..." should read “...the serial T2*-weighted images..." On page 1903, Table 2, an asterisk is missing at the top of the "Cho/Cr" column. 


\section{Neurology}

\section{Randomized controlled phase II trial of glatiramer acetate in ALS \\ Neurology 2006;67;920}

DOI 10.1212/01.wnl.0000244478.20128.b8

This information is current as of September 11, 2006

\section{Updated Information \&} Services

Permissions \& Licensing

\section{Reprints}

including high resolution figures, can be found at: http://n.neurology.org/content/67/5/920.1.full

Information about reproducing this article in parts (figures,tables) or in its entirety can be found online at:

http://www.neurology.org/about/about_the_journal\#permissions

Information about ordering reprints can be found online:

http://n.neurology.org/subscribers/advertise

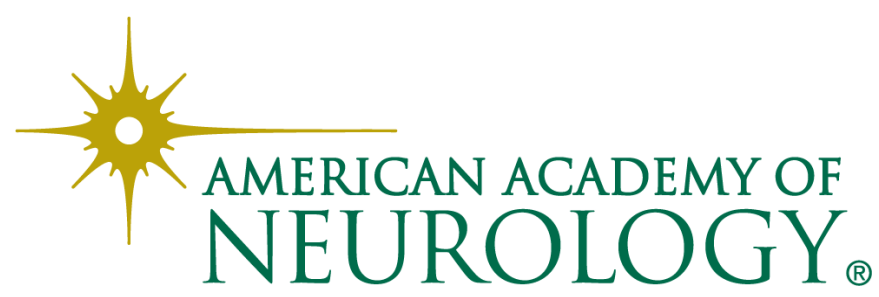

